\title{
ОБРАЗ ПИСАТЕЛЯ-ХУДОЖНИКА КАК КОММУНИКАТИВНЫЙ ФЕНОМЕН
}

\author{
Мария Кущиди \\ IMAGE OF A WRITER-ARTIST AS A COMMUNICATIVE PHENOMENON
}

\author{
Maria Kushida
}

\begin{abstract}
Резюме: Статья посвящена анализу иллюстративного творчества отечественных писателей первой четверти 19-го века. Особое внимание обращается на определение термина «писатель-художник», а также на приемы создания образа писателя-иллюстратора в произведении художественной литературы. В заключение делается вывод о взаимосвязи литературы и живописи (на примере интерпретации творчества мастеров слова, создающих иллюстрации к своим произведениям), а также об уникальной коммуникативной природе образа писателя-художника.
\end{abstract}

Ключевые слова: писатель-художник, художественный образ, произведение художественной литературы, иллюстрация.

Annotation. The article analyzes the illustrative work of Russian writers of the first quarter of the 19th century. Special attention is paid to the definition of the term "writer-artist", as well as to techniques for creating the image of a writer-Illustrator in a work of fiction. In conclusion, we draw a conclusion about the relationship between literature and painting (on the example of interpreting the creativity of word masters who create illustrations for their works), as well as about the unique communicative nature of the image of the writer-artist.

Key words: writer-artist, artistic image, work of fiction, illustration.

DOI: $10.14712 / 9788076032088.16$

«Живопись - это немая поэзия, а поэзия - это слепая живопись». Леонардо да Винчи

Писатель - многогранная личность, способная бесформенное облачить в форму, а сложное для понимания сделать очевидным. Выражая в художественном тексте философию своей души, мастер слова создает отдельный мир, в котором полновесно представляется жизнь народа, а через народ, как известно, передается эпоха, завуалированная образами, которые авторы наделяют особым предназначением - хранить историческую память о прошлом, говорить с будущим и видеть настоящее. Однако прямым орудием воплощения этой авторской миссии зачастую выступает не только слово, но и иллюстрация, заостряющая внимание читателя на важных аспектах художественного текста: образной системе, сюжетных перипетиях, конфликтах героев, символике и т.п. Отметим, что нередко иллюстрируют свое творчество сами писатели, а следовательно, имеет значение, рассуждая о литературе как виде искусства, говорить об особом образе художника слова - писателя-иллюстратора.

Однако, изучив доступные нам научные источники, мы пришли к выводу, что понятия «писатель-художник», «писатель-иллюстратор» практически не охарактеризованы в 
искусствоведческой и лингвистической науках, а особенностям создания художественного образа мастера слова, создающего иллюстрации к своим произведениям, не уделено внимания вовсе. В связи с этим, опираясь на работы В.А. Доманского, К.В. Пигарева, Е.В. Потемкиной, Н. Ратковски, мы самостоятельно сформулировали рабочее определение ключевого термина нашего исследования. Отметим, что понятия «писатель-художник» и «писатель-иллюстратор» мы рассматриваем как синонимы. Итак, писателем-художником мы называем мастера слова, самостоятельно создающего к своим произведениям иллюстрации, имеющие значение для понимания смысла художественного текста. Важно отметить, что жанровая палитра используемых писателями иллюстраций может быть самой разнообразной.

Под иллюстрацией мы понимаем графическое изображение, которое визуально поддерживает повествование и реализуется в виде какой-либо “говорящей» для автора «картинки» (Пигарев 1972, 28). Исходя из данной трактовки, несложно прийти к выводу, что иллюстрация упрощает понимание художественного текста, существуя с ним во взаимодополняющей связи.

Не менее важен для нас и термин «иллюстратор», под которым мы понимаем творческую личность, создающую зарисовки (рисунки) к произведениям своего или чужого словесного творчества. Так, роль иллюстратора важна при создании единого поликодового, т.е. семиотически разнородного, текста.

Изображения, переплетаясь с вербальной основой произведения художественной литературы, тесно связаны друг с другом (Пигарев 1972, 106). Именно поэтому понять отдельно взятую сюжетную иллюстрацию невозможно. Необходимо исследовать каждую "картинку», композиционно соотнести все иллюстрации текста и, что не менее важно, провести связующие линии от рисуночного художественного образа к словесному.

Исследователи выделяют три основных функции иллюстративного сопровождения художественного текста: информативную, эмоционально-психологическую и эстетическую. Содержательное значение иллюстрации позволяет визуализировать основные сюжетные моменты повествования, представляет читателю дополнительную информацию, активизирует его эмоционально-познавательную деятельность. Эмоционально-психологическая фуннкция вызывает у читателей эмоциональный отклик, призывает их к субъективному погружению в художественную действительность. Эстетическая функция производит воздействующий эффект, оказывает влияние на воспитание в человеке лучших морально-этических качеств, формирует вкусовые предпочтения и развивает в человеке чувство прекрасного.

Рассуждая о значении иконического компонента в художественном тексте, мы пришли к выводу, что иллюстрация, дополняя вербальную природу литературного произведения, в совокупности со словом создает уникальный художественный образ, придуманный фантазией писателя, особенно если речь идет о самостоятельном создании автором иллюстраций к своему произведению. В связи с этим мы решили обратиться к трактовке еще одного научного понятия художественного образа. Итак, под художественным образом мы понимаем: 1) способ освоения действительности, свойственный только искусству; 2) обобщенную и в то же время конкретную картину действительности, созданную с помощью вымысла автора и используемых им средств художественной выразительности, придающих произведению искусства эстетическое значение (Доманский 2010). В произведениях литературы, сопровожденных иллюстрациями, художественный образ имеет многослойную природу, так как создается за счет средств различных видов искусства - живописи и литературы. Поэтому, чтобы понять тот или иной образ, а также воплощенный в художественном тексте образ автора, нужно учитывать взаимосвязь разнородных 
средств его создания, что, в свою очередь, придает такому образу особую коммуникативную природу.

При этом отметим, что в тексте произведения художественной литературы писателииллюстраторы могут использовать самые разные жанры нефотографических, то есть рисованных, иллюстраций. На наш взгляд, жанровые предпочтения мастеров слова в области живописи, воплощенные ими же в собственном художественном тексте, позволяют определить специфические черты личности писателя, а следовательно, более точно охарактеризовать образ автора в конкретном произведении литературы. Именно поэтому в своей статье мы решили обратиться к характеристике жанрового разнообразия иллюстраций, которые когда-то были созданы к собственным произведениям известными классиками отечественной литературы. $\mathrm{K}$ таким иллюстративным разновидностям мы отнесли: 1) с точки зрения композиционной значимости - фронтиспис, заставку, концовку, полосную, разворотную, оборочную иллюстрации, рисунки на полях и др.; 2) с точки зрения содержательного наполнения - пейзажи, портреты, автопортреты, «народные» картинки, карикатуры на общественные пороки и др. Отметим, что представленный репертуар нефотографических иллюстраций был сформирован нами на основе анализа творчества таких русских писателей, как А.С. Пушкин, Н.В. Гоголь и М.Ю. Лермонтов. Перейдем к более подробной характеристике названных иллюстраций.

Фронтиспис представляет собой заглавную иллюстрацию, которая размещается на левой половине первого разворота книги, правую сторону которого занимает титульный лист. Активно встречается в черновиках А. С. Пушкина, М. Ю. Лермонтова, Н. В. Гоголя в образах легких, незатейливых зарисовок, а также штрихов, «завитушек», подчеркивающих название литературного произведения.

Заставка помещается вверху страницы в начале части, главы или всей книги; служит средством сосредоточения читательского внимания на новом материале, помогает эмоционально подстроиться под него. Чаще всего заставочные иллюстрации изображают сцену, показанную в начале главы, акцентируют внимание на главной теме конкретной главы или части, детально показывают место действия, обстановку либо пейзаж, которые должны вызвать у читателя определенное настроение. Представленный вид иллюстрации делится на предметнодекоративный, который указывает на определенные бытовые детали, и символический, интенция которого - сформировать у читателя за счет многозначных образов полную картину происходящего.

Концовка располагается в завершении части, главы или всей книги. Она призвана вызвать эмоциональный отклик у читательской аудитории, подвести к определенным размышлениям и выводам. Концовки бывают сюжетно-тематическими, орнаментальнодекоративными и символическими. Являясь одним из самых распространенных видов иллюстрации, концовка нашла свое широкое применение в работах трех рассматриваемых нами писателей-художников.

Полосная иллюстрация занимает всю страницу, на которой ее помещает автор, а полуполосная занимает лишь часть, половину отведенной страницы. Выбор между полосным и полуполосным форматами иллюстраций зависит от важности изображаемого сюжетного события, образа, действия. Содержание таких иллюстраций неразрывно связано с предыдущими или последующими событиями литературного произведения. Чаще всего полосный формат иллюстрации отбирается автором для обозначения важного смыслового события текста. 
Оборочная иллюстрация представляет собой небольшой рисунок, вокруг которого размещается словесный текст произведения литературы. Ее вкрапление в художественный текст позволяет автору акцентировать читательское внимание на конкретном сюжетном жесте или детали (Лебедева 2010, 43). Такой вид изобразительного творчества часто использовался Н. В. гоголем.

Рисунки на полях выносятся за границу текста и используются в тех случаях, когда иллюстратору важно показать какое-либо менее значимое событие (Лебедева 2010, 44). Зарисовки вне текста - яркая черта иллюстраций А. С. Пушкина.

Все охарактеризованные иллюстрации представлены в приложении к статье.

Перейдем к характеристике иллюстраций по содержательному признаку. Так, А. С. Пушкин делал предпочтение созданию иллюстраций в жанре портрета и автопортрета. Именно в его художественном творчестве разводятся, казалось бы, два близких по значению термина иллюстрация и автоиллюстрация (Наумкина 2011, 57). Поэт тщательно выбирал образ для создания иллюстрации, часто создавая и свой собственный графический портрет. Особенное внимание А.С. Пушкин уделял созданию иллюстраций, желая как можно сильнее детализировать и «оживить» для читателя мир художественного пространства.

Иллюстрации А. С. Пушкина отличаются своей легкостью и необдуманностью, т. е. в них нет никакого сложного внутреннего подтекста, на основе которого можно было бы сказать, что эти рисунки были созданы писателем с определенной масштабной целью. Во время работы над своими зарисовками автор не учитывал их значимость для произведения, они даже не предназначались для сопровождения художественной мысли.

Однако большую роль играет идея о том, что все свои иллюстрации А. С. Пушкин делал для «настроя» на работу над произведением, создавая их как «вдохновляющий багаж» для творчества. Он рисовал, когда не мог определиться с нужным словом, с образом и характером персонажа и даже когда продумывал, как будет звучать голос и выглядеть профиль любимых персонажей. Именно это отличает А. С. Пушкина от остальных писателей-художников, дает исследователям большую базу для изучения души писателя, находящегося в состоянии вдохновения (Чудинов 2007).

Так, иллюстрации А. С. Пушкина дают уникальную возможность рассмотреть физиологические черты писателя, ближе узнать его личностные особенности и выяснить, что же на самом деле испытывал на себе писатель, полностью погруженный в творческие искания.

В иллюстрациях другого мастера слова - Н. В. Гоголя было определенное таинственное очарование, которое передает сложную философскую реалию души человека и его одухотворенности (Баротти 1981). Идея автора о тесной связи духовного мира человека и искусства была центральной в его творчестве, и все детально вырисованные портретные образы несли сложную мысль постижения и сохранения прекрасной души, за которую Гоголь отчаянно боролся (Баротти 1981, 8).

Эстетика Н. В. Гоголя тесно связана с эстетикой Ренессанса, где платоническое понимание искусства воплощается как высшая, божественная духовная красота. Писатель строго придерживался и следовал идее силы, духовно преображающей человека, возвышающей его как существо высшей духовной организации, достигнувшей определенной точки развития (Баротти 1981).

Для Н. В. Гоголя наиболее частыми и значимыми жанрами иллюстративного творчества были изображения домашнего быта Малороссии. Писатель с особой аккуратностью и внимательностью делал наброски ковров, на которых трепетно вырисовывал узоры, среди 
которых частыми образами были птицы и цветы. Писатель в своих так называемых «народных картинках» отражал множество этических и социальных тем, среди которых особенное внимание он уделял религиозному, сочетаемому с нравственными эталонами и идеями, историческому, тесно переплетенному с военным и литературным, а также героическому, сказочному контекстам, где основная мысль автора базировалась на наставлениях подрастающему и взрослому поколениям. Также иллюстрации Н. В. Гоголя нередко передавали комическую и карикатурную сторону окружающей его жизни с целью отобразить греховность и несовершенство человеческого общества, его сознания и духовного развития.

Ранний Н. В. Гоголь был увлечен поиском идеального. Конечно, с развитием творчества писателя эти искания не закончились, а лишь активно продолжились, но стоит обратить внимание на то, что на начальном этапе творчества автор вдохновлялся гравировками малоросской церкви. Это оказало на него сильное влияние, отразившись на мировоззренческих эталонах мира реального и ирреального (Наумкина 2011).

Среди иллюстраций Н. В. Гоголя также можно найти портреты писателей, среди которых - большое количество изображений профиля А. С. Пушкина. Однако писатель не ограничивался созданием образов реальных людей, он также активно создавал иллюстрации своих персонажей, придавая им «демонические», пугающие черты, что обуславливается поисками писателя духовного эталона и обличением греховного в выдуманных им же реалиях.

М. Ю. Лермонтов уделял основное внимание словесной эстетике текста, а зарисовки к произведениям создавал лишь за острой необходимостью выделить духовную суть значимых для сюжета героев. Так, писатель тщательно прорисовывал улыбки и глаза своих персонажей, оставляя другие детали в тени (Доманский 2010, 41). С помощью иллюстраций он давал читателю установку на понимание его текста, на возможность расшифровки образа с помощью культурно-типологического сопоставления его героев с реальными историческими личностями (Доманский 2010, 42).

Так, например, акварельный портрет В. А. Лопухиной-Бахметьевой Н. Пахомов связывает с образом Веры из известного романа «Герой нашего времени». М.Ю. Лермонтову точно удалось изобразить образ своей возлюбленной, создав его «живым», способным выражать сильные эмоции задумчивости и грусти. Конечно, большого и тесного сходства портреты возлюбленной Лермонтова и его героини Веры внешне не имеют, однако между этими двумя образами прослеживается сложная психологическая связь - сильный, выносливый характер обеих девушек (Наумкина 2011, 42).

Стоит отметить, что иллюстрациям М. Ю. Лермонтова ранее не придавалось большого значения, поскольку они не входили в черновики его произведений, являясь полностью самостоятельными произведениями художественного творчества. Однако со временем, когда литературное творчество писателя получило достаточное обоснование и огласку, исследователи впервые обратили внимание на роль рисунков автора, выделив их как отдельную часть его творчества.

Иллюстрации писателя зачастую называют именно зарисовками, поскольку все его работы сделаны карандашом и не представляют собой законченного произведения искусства. Однако именно с их помощью М. Ю. Лермонтов передает напряженность, драматизм конкретных сцен своих произведений, что значительно усиливает их влияние на читательскую аудиторию.

В числе тематически разнородных рисунков М.Ю. Лермонтова исследователи выделяют иллюстрации на военную тематику, живописные пейзажи, портреты и автопортреты, 
карикатуры, рисунки безотносительно к натуре, а также изображения невоплощенной композиции (Наумкина 2011, 41).

Подводя итоги, следует отметить, что личность писателя, неоспоримо оригинальная, глубокая и богатая, зачастую таит в себе множество идей, которые нам как читателям следует разгадать. Нередко подсказки к этим загадкам писатель щедро раздаривает своим современникам и потомкам в блестящих произведениях словесного творчества, однако дополнительными смыслами обладают иллюстрации, записи и формулы, которыми писатели могут сопровождать свой текст. Именно поэтому, на наш взгляд, так важно изучать и черновики мастеров слова, чтобы раскрыть глубину идейно-тематической природы их произведений. Во многом такому пониманию может помочь иллюстративное творчество писателей. В связи с этим мы сделали вывод, что художественный образ писателя-иллюстратора может создаваться за счет самых разнообразных приемов. В их числе мы выделяем: а) жанровые и тематические предпочтения мастера слова в области литературы и живописи как видов искусства; б) выбор писателем-художником технических особенностей иллюстрирования своих текстов (выбор орудия для рисования - карандаша или пера, цвета, соотношения света и тени в рисунке и др.); в) акцентирование смысловой и ассоциативной связи рисунка и слова с помощью содержания самой иллюстрации или подписи к ней; г) количество иллюстраций и их расположение на странице текста. Все перечисленные нами приемы помогут читателю глубже проникнуть в идейный замысел художественного текста и в то же время раскрыть уникальную личностную природу автора.

\section{Использованная литература/ Referemces}

БАРОТТИ, Т. (1981): Взгляды Гоголя на искусство и эстетику их отражения в его творчестве. Москва, 1981. С. 37-52.

ДОМАНСКИЙ, В. А. (2010): Литература в синтезе искусств. Санкт-Петербург : Изд-во СПгУТД, 2010. 362 С. ISBN 978-5-7937-0548-6.

ЛЕБЕДЕВА, Е. А. (2010): Особенности создания иллюстрации как вида прикладной графики : специальность 03.08.00 «Изобразительное искусство» : дипломная работа. Петрозаводск, 2010.78 с. Место защиты: ГОУ ВПО «КГПА».

НАУМКИНА, Ю. А. (2011): Внутритекстовая связь литературы и изобразительного искусства как педагогчческая проблема // Педагогический журнал : методика обучения и воспитания. АнжероСудженск, 2011. С. 53-66.

ПИГАРЕВ, К. В. (1972): Русская литература и изобразительное искусство : очерки. Москва : Наука, 1972. $155 \mathrm{c}$.

ПОТЕМКИНА, Е. В. (2006): Психологический анализ рисунка и текста. СПб : Речь, 2006. 524 с. ISBN 5-92680362-4.

РАТКОВСКИ, Н. (2017): Профессия - иллюстратор. Учимся мыслить творчески. Москва : Манн, Иванов и Фербер, 2017. 327 с. ISBN 978-5-00100-878-1.

чУдинОВ, В. А. (2007): Тайнопись в рисунках А. С. Пушкина. Москва : Поколение, 2007. 488 с. ISBN 978-59763-0021-7.

\section{Профиль автора:}

Мария Кущиди, студентка 3 курса факультета филологии Новокузнецкого института (филиала) ФГБОУ ВО «Кемеровский государственный университет»

Научный руководитель: Любовь Викторовна Гордеева, кандидат педагогчческих наук, доцент 
Научные интересы: коммуникативная культура педагога-филолога, речевая практика современников, жанры речи, теория и методика обучения русскому языку и литературе, школьное и вузовское филологическое образование.

e-mail: lyuba.gordeeva.85@mail.ru

Место работы: Новокузнецкий институт (филиал) ФГБОУ ВО «Кемеровский государственный университет», факультет филологии, кафедра русского языка и литературы; г. Новокузнецк, ул. Радищева, д. 34, кв. 21, индекс: 654086, Россия.

\section{Author's profile:}

Maria Kushida, 3rd year student of the faculty of Philology of Novokuznetsk Institute (branch) Kemerovo state University

Scientific supervisor: Lyubov Viktorovna Gordeeva, candidate of pedagogical Sciences, associate Professor Research interests: communicative culture of a philologist, speech practice of contemporaries, genres of speech, theory and methods of teaching Russian language and literature, school and University philological education. e-mail: lyuba.gordeeva.85@mail.ru

Place of work: Novokuznetsk Institute (branch) Kemerovo state University, faculty of Philology, Department of Russian language and literature; Novokuznetsk, 34 Radishcheva str., sq. 21, index: 654086, Russia.

\section{Приложения}

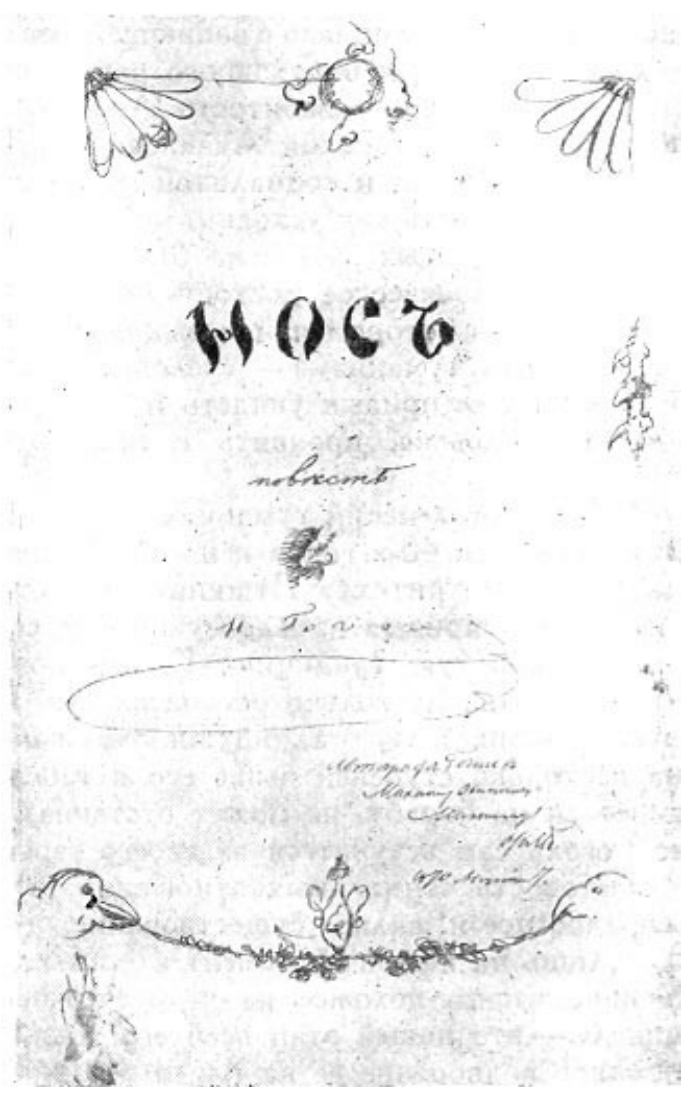

№1. Н.В. Гоголь «Нос» (фрронтиспис)

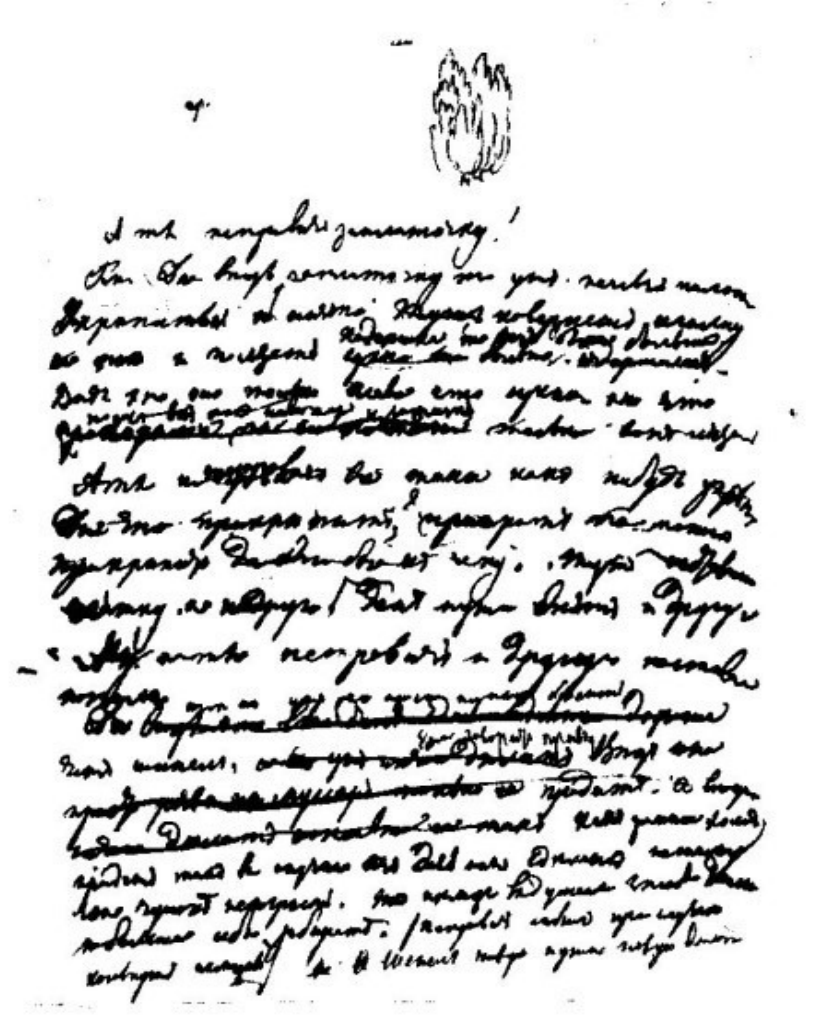

№2. Н.В. Гоголь. Черновой автограф (заставка) 

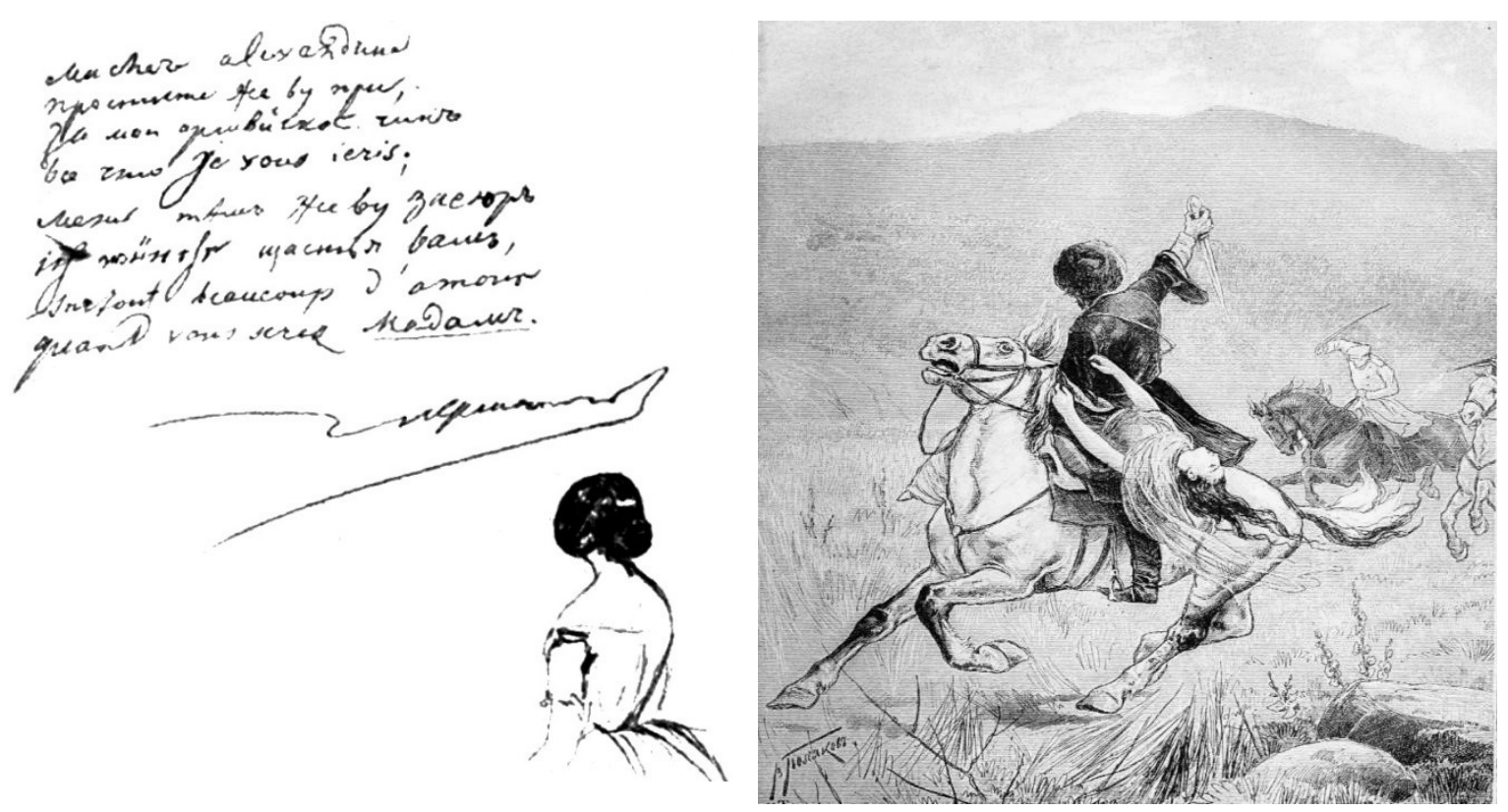

№3. М.Ю. Лермонтов «А.А. Углицкой №4. М.Ю. Лермонтов «Герой нашего времени» (MA CHERE ALEXANDRINE)» (концовка) (полосная иллюстрация)

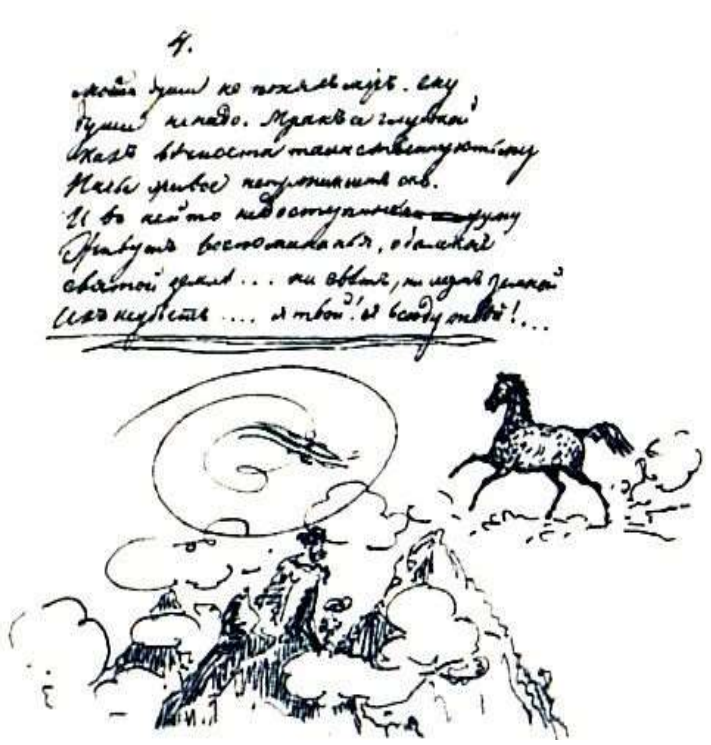

№5. М.Ю. Лермонтов «Аул Бастунджи» (полуполосная иллюстрация)

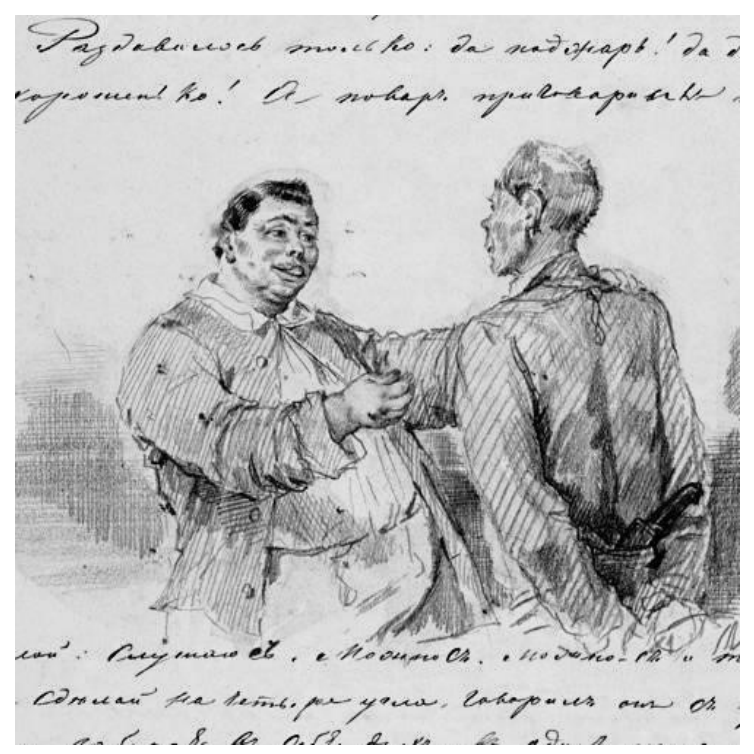

№6. Н.В. Гоголь «Мертвые души» (оборочная иллюстрация) 


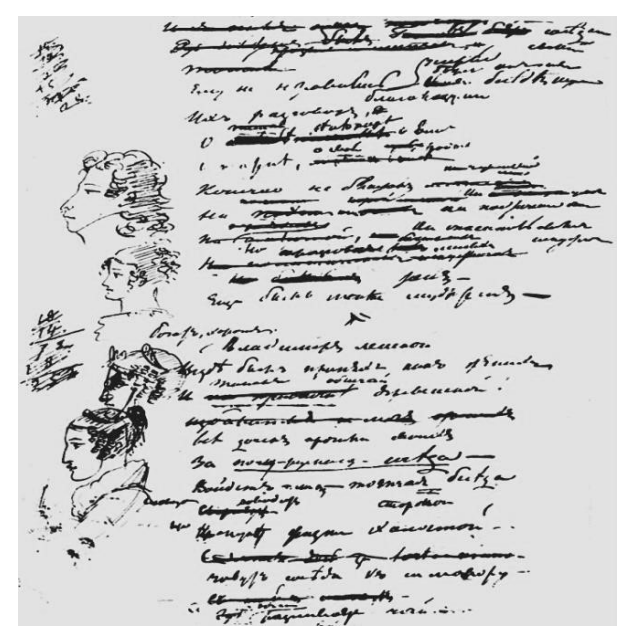

№7. А.С. Пушкин «Евгений Онегин» (рисунки на полях) 